\title{
COGNITIVE DETERMINANTS OF THE EFFECTIVENESS OF TECHNOLOGICAL INTERFACES
}

\begin{abstract}
Interface plays an important function in the operational process of modern interactive information technologies. Its task is to enable communication, signal exchange, and cooperation with the human mind. Technological interface is understood as the place where technology and software operating a computer must enter into interaction with the mind. The response is provided by the mind, which communicates with the machine performing the tasks imposed by the mind. The technology with its complexities can be a problem for the operator, but on the other hand, the person can also be a problem for the technology by vague and unspecified tasks transferred for execution. I would like to view various aspects of the functioning of the interface by analyzing the four modalities: perceptual modality, associated with memory and experience, with the expectations of users, and conceptual modality related to understanding of the technology by the user.
\end{abstract}

Keywords: user interfaces, communication, human interaction, usability, mindcognitive processes.

\section{Introduction}

Interface is understood as the tool responsible for human interaction with a device or software. It is the space in which the interaction of the user and the machine occurs. This is usually the part of the software which is designed to handle input/output devices. Like in smartphones, interaction with the user is ensured by the operating system. The standardized design of its individual applications allows for rapid cooperation with the human mind. Efficient operation and feedback control provided by the interface enables and simultaneously facilitates the control and decisionmaking of the user. Psychological knowledge regarding the signal processing capabilities of the human and knowledge of the utility of applications play an important role in these processes. According to the definition 
of J. Nielsen - an expert in the field of usability, this is a collection of five elements:

- learnability

- efficiency

- memorability

- errors

- satisfaction

All this adds up to usability: ease of use at first contact with the product, and how effectively it is used during repeated contact, or after a long break. How it is possible to deal with encountered errors, and the satisfaction that can accompany us when using the product. The dynamic development of technology has led to development in the area of functionality and design principles aimed at the user's convenience and ease of use, thanks to which we do not think about how things work. We can use products, and more importantly, we can achieve the desired goal with their help.

However, before we achieve the optimal effect we have to implement several methods to determine which components are to be changed/improved. This process, which we call optimization, can be enhanced by heuristics developed by Jakob Nielsen. They represent only a set of general guidelines, but still it is worth getting familiar with them. "10 heuristics of J. Nelsen" will not show us the exact solutions and options that should be considered during the design stage (Nielsen \& Mack, 1994). They will show us the general principles of building effective interaction between man and machine, and the factors most influencing the opinion of the user during operation regarding satisfaction and comfort. I would like to look at aspects of the functioning of the interface through the prism of scalable web sites (Henderson, 2007, p. 242) the user comes into contact with every day on the Internet. Comments will refer to the enlarged space of interaction, taking into account the flexibility of the software for each hardware which enables control of events related to the operation site. The computer, laptop, and more and more often a smartphone have become a window of communication.

\section{Visual perception}

Eyesight is one of the most important senses ensuring the functioning of humans. Each of us perceives the environment around us differently (interpretation). However, the reception has components which are common to most of us and that are clearly understood by most of us. Software features 
enhancing its positive reception are usually clearly defined and exposed to encourage the user. Quality of use has become an art appreciated by software producers. This is the role of the interface, which we see as an element ensuring our human communication with the software and that allows for interaction. The perception of visual information via the interface may range in form from a text to imaging. This enables us to interpret stimuli that are contained in the transmission. It also allows for their selection. Web sites and their efforts to effectively build their image involve several components efficiently acting on the perception.

\section{Typography}

Typography is governed by certain laws, which can be also considered as an art. The readability of text on the screen is influenced by the size of the font and its typeface. It is widely accepted to use serif fonts for longer texts, which are supposedly read easier and faster, and no serif fonts for the headers. Designers of software interfaces, as well as those involved in the web design are not restricted to standard and commonly used fonts. With the new capabilities included in the specification of style sheets attached to the site, it is possible to view a variety of custom fonts that match the project without the need to install them in devices which display interface with text on the screen. The readability and ease of reading is also affected by line length. With scalable screen size, it is important to adjust the paragraphs to those needs of the screen size, and for lines to scroll automatically. The smoothness of a text constructed in this way eliminates the uncomfortable option of a horizontal scroll bar. Spacing or line spacing should not be too small, so that the text is not merged - the human eye can then easily get lost in the text. Too large distances make it difficult to take sight of consecutive lines (Felici, Romano, 2009, p. 120). All these parameters can be adjusted from the style sheet, setting appropriate options depending on the size of the screen. Typography is a field that is characterized by fairly complicated rules and concepts that have evolved over many years (Goody, 2012 , p. 83). This knowledge allows you to create a clear and understandable interface.

\section{Color}

A well-chosen combination of colors is a key element of graphic design of interfaces. It affects the recipient and may cause relevant associations and emotions (confidence, anxiety, satisfaction). When designing web sites, it is accepted not to choose too many colors (usually 4 or 5), which should include a color reserved for alerts. Interface sites, constructed in 
this way, are seen as consistent and transparent projects. Choosing colors for a project might be assisted by Internet applications offering readymade color combinations or solutions where, according to our own preferences, we can choose the colors under certain conditions relating to their composition.

Multiple interfaces can change the color combinations depending on the user's preference. The purpose of the use of color themes is to attract a user's attention. They can emphasize selected and important parts of the interface and increase the storage of key features for operation. They can positively affect the image and advertise the product (Szczęsna, 2003, p. 18), which is a computer program, an application on a smartphone, or a web site.

It is worth remembering that a small percentage of the population has impaired perception of color. The perception of color combinations for this group is different than for the rest of the population. It is therefore important to test the design of the appearance of the interface, basically its readability, also for minorities. The Internet offers applications that allow testing selected color combinations ("Colblindor | All about Color Blindness").

\section{Arrangement of elements (logo, menu, breadcrumbs)}

Properly chosen and thought over typography with a clear color scheme will increase the readability of built interfaces. But we should not forget that we are still missing some key elements for the project to be complete. Logo is one of them - this is the element of everyday contact. Computers, television sets, monitors, smart phones, clothes, food - brand logos are everywhere. The versatility of a well-designed logo usually has the form of a symbol, which is understood regardless of the language (Airey, 2009, p. 11). Logo design is a demanding activity directed by certain rules. David Airey describes in his book "Logo Design Love: Design brilliant logo!" the seven key elements of a perfect logo design: do not complicate, relevance, drawing from traditions, uniqueness, falling in memory, small is beautiful, and focus on one aspect (Airey \& Sałbut, 2010, pp. 38-39). Logo is the representation used by companies, products, people, campaigns, or organizations (Hardy, 2012, pp. 17-18). It allows you to stand out from the competition, and to build a visual identification. Graphic designs of interfaces of websites usually have the logo placed in the header on the left side. A common procedure is to glue it permanently in this position, so it remains visible even if we scroll the page down.

Besides the logo, readability in navigating the site structure is also important for the user. This requirement may be satisfied through the catego- 
rization of content and detailed or general access to it through the appropriate menu items. Breadcrumbs is an additional advantage allowing for greater transparency and orientation in the structure. It is usually placed directly over the viewing content. It contains full information about the nesting of the viewed content in the structure. Through appropriate references in its construction, it allows reaching levels that are higher than those currently being viewed. When constructing interface sites, usually fixed components of every page go in the places to which we are accustomed - this shortens the time it takes to find relevant content on the menu items. It simplifies e.g. the search for contact information, going to the home page. A suitable system the user is accustomed to and which is also based on eye tracking 1 guarantees interface readability.

The above mentioned elements do not cover the full range of possibilities, but they are important enough to be listed. The design of interfaces for smart gadgets (e.g. SmartWatch) is a challenge for today, as it is characterized by an even smaller screen than of smartphones. So typography, color, contrast and space, logo, positioning components constitute the effectiveness of interfaces.

\section{Memory and experience}

If we treat memory as the ability to collect and extract information from past experience, the ability will be useful to us in contact with interfaces. They are close to each other in structure to use, and offer similar functionality. With memory and user experience resulting from the use of interfaces, the concept of user-centered design (UCD) is connected. The experience we have is useful on the line of human contact with technology and guarantees time saving. When designing and developing a project aimed at the user, the speed of progress and its quality are important. Used processes can be grouped into two categories: one associated with the waterfall model, the second with the agile approach (Chudley, Allen, 2012, pp. 35-36). The first-mentioned model involves programming in stages. It collects and describes the requirements on the basis of creating the project, the correctness of which is checked at the end - as it can be described with simple words. This is a classic model used in information technology. It has its advantages and disadvantages. Due to the latter, the method called agile programming was developed. Its most important objective is the observation of customer requirements, which change during the project. The description of this method is called Agile Mani- 
festo, which includes a set of four of the following values (Shore \& Warden, 2008, p. 22):

- individuals and interactions rather than processes and tools;

- operating software rather than complete documentation;

- cooperation with the customer more than the contract negotiations;

- responding to changes rather than proceeding according to plan.

Determining who will use the designed interface, and what functions will be useful is to increase the pleasure of use of the product, which will also translate into ease of use and interaction with the user. The finished projects often have written text converted to a graphic in the form of icons. It is much easier to memorize images than text. Hence the appearance of symbols such as a house or an envelope clearly brings the association with the action that will be executed when clicked. Go to your home, send messages, make a call, etc. Text messages have been permanently replaced by symbols, which are all clearly associated by us, we memorize them and preserve through subsequent experience with the interface. Examples of text replacement by icons can be multiplied. The projects of interface sites can contain ready-made icon sets. Font Awesome is very popular, which is an impressive collection of vector icons and it currently contains approximately 634 symbols ("Font Awesome, the iconic font and CSS toolkit"). By using icons we gain space by replacing text, but also versatility regardless of the language. Seeing a specific icon, we know what event has been assigned to it. Virtually every interface will have a similar structure and recorded functionalities. Frequent activities tend to be available "on top" in the structure of the interface. Advanced options are hidden deeper. The modality of software, however, allows for any configuration of its elements, so the structure of the interface can be extended with commands that were hidden deeper. Customizing needs may result from the customs and habits which we record in everyday contact with selected programs. Sites also offer the option of personalized settings. It is usually available after registration, thanks to which we are identified. We can customize what messages have to reach us in the first place, which blocks of pages are important to us, and which we can ignore. Smart tips are an interesting option for less experienced users.

They usually appear when we wrongly enter the data in the form, when we use unacceptable characters, in the absence of correctly typed text, etc. They are designed to facilitate handling and correct common errors and ambiguities in communication between the user and the interface. 


\section{Expectations of the user}

The user's expectations are included within two concepts supporting communication between man and machine. UX (user experience) by definition is "a whole of sensations experienced by the user when using the interactive product" 2 . Designing those associated with it is geared to user interaction, which is expected to provide a positive experience. The attractiveness and satisfaction of use is put in first place and implemented using the aforementioned methods of user-centered design. Understanding the needs and expectations of a future user is also very important in the context of intuitive handling. These needs are tested, and functionalities integrated into the interface are improved. The websites for user experience architecture include the following dimensions defined by Peter Morville:

- Findability - the possibility of finding a website, application, product or service by the user. This term consists of a proper terminology, the possibility of finding the page in a search engine (SEO), marketing communication,

- Desirability - effective presentation to the user, the value of visual communication,

- Credibility inspires user confidence; the product has to fulfill the purpose for which it was created,

- Accessibility - product customization for the disabled, equal and correct operation regardless of the system used, browser or device screen size,

- Usability - convenient and easy to use,

- Usefulness - meeting users' needs (Rosenfeld, Morville, 2003).

UI (user interface) is the second concept which is defined as a space in which the user interacts with the machine. It is part of the software responsible for communicating with the user. The most common interface has the form of graphical interface (GUI) and a web interface that is displayed using a web browser. Others include: command line-text or voice.

These concepts, UI and UX, are equally important and complement each other. It is not difficult for us to imagine or recall the application that looks great, but is completely incomprehensible to operate. This gives us an example of the application of great UI with very bad UX. User expectations, if not met, can lead to extreme reactions from surprise to aggression. Therefore, the technology interface informs us about the progress of the executed commands, the percentage progress of the action. In a short time after the command and the failure of the software we need to get feedback indicating 
whether there is an error or that the program is still working. This provides ease of use and meets the expectations of the user, which should not be left without feedback.

\section{Conceptuality}

Conceptual modality associated with the recognition of the technology by the user should answer the question: Why and for what should the program/machine interact with the user? This can be seen as time saving. By performing commands, the interface corresponds to what is going on right now, which stage it is, if the command is doable, or is poorly constructed and its execution will lead to error. Design of interactions that occur during a program, influence the formation of valuable relationships between users of programs or internet services. They bring the dynamic relationships that exist between the user and the program. Usability is also increased. Interface or a web site with their functionalities offer users versatility and the ability to integrate with other services. You can also see the dark side here, which might lead to dependence on using the tool: a need to keep checking if something has changed, whether a new message has appeared, whether any new information may indicate a disorder. Another aspect of security is widely understood as the security of the data we leave in applications or services. Safety of the application - what happens when you execute a command, or when I press something accidentally? Is the technology that we use every day resistant to damage caused by user errors? Is it susceptible to attack from the outside that can cause great damage?: Loss of important data, leakage of private information, preventing the damage of proper operation of both programs and network applications.

The dynamic development of technology creates a problem of "functional equivalence". Programs from different manufacturers meet the same functions while having a different interface, colors and graphics, layout of commands. However, as a result of their use, we achieve the same or a very similar effect. The final result can, however, be problematic in terms of interchangeability of future use in another program. Here we encounter the problem of translatability. The file coming from one device does not have to be correctly read in another program. Problems can also occur within the use of a single program. A newer, richer in options, version may be unreadable or read errors with older versions. Format compatibility is very important in the context of the availability of such archival data. It can 
cause a compulsion to use a single software or its earlier version, since the results of our work will not be read. These problems are often encountered with text files, graphics, or audio-visual materials.

\section{Summary}

The machine's heartlessness is undeniable as it carries out only preprogrammed commands. Incomprehensible interface will limit us to interacting with the machine, and performing simple activities can become too complex and prevent the user from using it. The interface appears on the contact line of communication between humans and technology. The better the interface is the more invisible it becomes to the user. Many interfaces show us the options and commands available in simplified form, often using icons instead of text, access to advanced options is achieved by switching to this mode. It is often too complicated to be used by the casual user, and is recommended only for people with advanced knowledge of the configuration of the program. For example, you can use the anti-virus program, which in the basic version decides about most of the activities based on the stored configuration patterns. In the advanced version, we can determine which inbound and outbound packets to the network will be passed or blocked, and what steps are to be taken at detecting a break in the written rules. Handling the interface takes time, just like learning its operation. Today's interfaces are characterized by a certain similarity and similar commands, as well as their location. This reduces the time needed to learn. Habits once acquired are maintained using similar or identical commands in another interface. In almost every application, saving is marked with a floppy disk with an assigned keyboard shortcut $\mathrm{Ctrl}+\mathrm{s}$, similar to the search where the $\mathrm{Ctrl}+\mathrm{f}$ will display a window where you can enter a searched term. This saves time and we can memorize and preserve habits. Experience acquired previously pays off when using new programs. We are also not deprived of important feedback, which in many cases calms our fears as to the proper functioning of issued commands. It informs us about potential errors, prevents them from occurring, and even suggests what needs to be improved in the issued command to be executed. Friendly interface is designed by people who must have not only technical knowledge but must also be familiar with the social sciences. Observation and analysis of the activities of the human senses, mind-cognitive processes such as consciousness, memory, understanding, perception, and reasoning are used in built interfaces and in their improvement and effective operation. 


\section{N O T E S}

1 eye tracking - technique used for over 100 years in areas such as psychology, medicine, road safety, ergonomics, human-computer interaction and marketing. Source: https://pl.wikipedia.org/wiki/Okulografia access: 30.08.2016.

2 Source: https://pl.wikipedia.org/wiki/User_experience access: 30.08.2016.

\section{B I B L I O G R A P H Y}

Airey, D. (2010). Logo design love: zaprojektuj genialny logotyp! (Logo design love: A Guide to Creating Iconic Brand Identities). Gliwice: Wydawnictwo Helion.

Chudley, J., Allen, J. (2012). Projektowanie witryn internetowych User experience. (Smashing UX Design: Foundations for Designing Online User Experiences). Gliwice: Wydawnictwo Helion.

Colblindor |All about Color Blindness. 30.08.2016, http://www.color-blindness.com/ Felici, J., Romano (2009). Kompletny przewodnik po typografi: zasady doskonatego sktadania teksu. (The Complete Manual of Typography. A Guide to Setting Perfect Type). Gdańsk: Czysty Warsztat.

Font Awesome, the iconic font and CSS toolkit. 31.08.2016, http://fontawesome.io/

Goody, J. (2012). Renesans: czy tylko jeden? (Renaissances. The One or the Many?) Warszawa: Spółdzielnia Wydawnicza "Czytelnik".

Hardy, G. (2012). Podręcznik projektantów logo: Smashing Magazine. (Smashing Logo Design: The Art of Creating Visual Identities). Gliwice: Wydawnictwo Helion.

Henderson, C. (2007). Skalowalne witryny internetowe: budowa, skalowanie i optymalizacja aplikacji internetowych nowej generacji. (Building Scalable Web Sites: Building, scaling, and optimizing the next generation of web applications). Gliwice: Wydawnictwo Helion.

Nielsen, J., \& Mack, R. L. (Red.). (1994). Usability inspection methods. New York: Wiley.

Rosenfeld, L., Morville, P. (2003). Architektura informacji w serwisach internetowych. (Information Architecture for the World Wide Web). Gliwice: Helion.

Shore, J., \& Warden, S. (2008). Agile development filozofia programowania zwinnego. Gliwice: Wydawnictwo Helion.

Szczęsna, E. (2003). Poetyka reklamy (Wyd. 1). Warszawa: Wydawn. Naukowe PWN. 